\title{
Article \\ Characteristics of Carbapenem-Resistant Gram-Negative Bacilli in Patients with Ventilator-Associated Pneumonia
}

\author{
Amira Mohamed ${ }^{1}$, Enas Daef ${ }^{2}$, Amany Nafie ${ }^{2}$, Lamia Shaban ${ }^{3}$ and Maggie Ibrahim ${ }^{2, *}$ \\ 1 Clinical Pharmacy, Women's Health Hospital, Assiut University, Assiut 71711, Egypt; \\ amirayousif10@gmail.com \\ 2 Microbiology and Immunology Department, Faculty of Medicine, Assiut University, Assiut 71711, Egypt; \\ deafenas@yahoo.com (E.D.); amanynafeh@yahoo.com (A.N.) \\ 3 Chest Department, Faculty of Medicine, Assiut University, Assiut 71711, Egypt; lamiashaban@yahoo.com \\ * Correspondence: maggie.abdallah@hotmail.com
}

check for updates

Citation: Mohamed, A.; Daef, E.; Nafie, A.; Shaban, L.; Ibrahim, M. Characteristics of Carbapenem-

Resistant Gram-Negative Bacilli in Patients with Ventilator-Associated Pneumonia. Antibiotics 2021, 10, 1325. https://doi.org/10.3390/ antibiotics 10111325

Academic Editor: Krisztina M. Papp-Wallace

Received: 19 September 2021

Accepted: 27 October 2021

Published: 29 October 2021

Publisher's Note: MDPI stays neutral with regard to jurisdictional claims in published maps and institutional affiliations.

Copyright: (C) 2021 by the authors. Licensee MDPI, Basel, Switzerland. This article is an open access article distributed under the terms and conditions of the Creative Commons Attribution (CC BY) license (https:// creativecommons.org/licenses/by/ $4.0 /)$.

\begin{abstract}
Carbapenem-resistant Gram-negative bacilli (CR-GNB) has become a global threat. In hospital settings, the association of CR-GNB with ventilator-associated pneumonia (VAP) is a critical public health concern owing to their high resistance rate to most antibiotics. The present study aims to identify the frequency of carbapenem-resistance and to determine the rate of multidrug resistance (MDR), extensive drug resistance (XDR) and pan-drug resistance (PDR) among CR-GNB infections in VAP. Antimicrobial susceptibility testing was carried out using the disk diffusion method and the detection of carbapenemases was screened using the imipenem-E test and the modified carbapeneminactivation method (mCIM). The isolates were verified by polymerase chain reaction (PCR) for the presence of $b l a_{\mathrm{NDM}}, b l a_{\mathrm{SPM}}, b l a_{\mathrm{VIM}}, b l a_{\mathrm{IMP}}$ and $b l a_{\mathrm{GIM}}$ genes. $89.5 \%, 14 \%, 17.5 \%, 10.5 \%, 3.5 \%$ of isolates exhibited the presence of $b l a_{\mathrm{NDM}}, b l a_{\mathrm{VIM}}, b l a_{\mathrm{SPM}}, b l a_{\mathrm{IMP}}$ and $b l a_{\mathrm{GIM}}$, respectively. $76 \%$, $17 \%$ and $7 \%$ of isolates were PDR, XDR, and MDR, respectively. Carbapenem-resistance genes were identified in a significant percentage and $b l a_{\mathrm{NDM}}$ was the most predominant gene. All isolates were highly resistant to most antibiotics. This health concern has proven to be a big challenge in developing countries such as Egypt, as it is associated with high morbidity, high mortality, and raised healthcare costs.
\end{abstract}

Keywords: carbapenem-resistance; ventilator-associated pneumonia

\section{Introduction}

Most seriously sick patients admitted to intensive care units (ICUs) reveal bad nutritional and general conditions, down immune status, prolonged hospital stays, and a history of invasive procedure and, consequently, they are vulnerable to increased propensity to infection [1].

Regardless of the various complications related to mechanical ventilation (MV), it is lifesaving for most of ICUs patients. One of these complications is ventilator-associated pneumonia (VAP) which is a highly prevalent hospital-acquired infection (HAI) in ICUs. VAP is allied with lengthy hospital and ICU stays, prolonged MV time, expanded hospital expenses, enduring morbidity, and increasing mortality [2].

Antimicrobial resistance (AMR) is a worldwide health concern due to its correlation with high morbidity and mortality and raised healthcare costs [3]. The problem of AMR is increasing globally with the spread frequently striking healthcare settings due to the improper use of antimicrobials and inappropriate infection control practices. AMR risk is especially in low- and middle-income countries [4].

Carbapenem-resistant Gram-negative bacilli (CR-GNB) are a threat worldwide. Carbapenem-resistant Enterobacterales (CRE), carbapenem-resistant Pseudomonas aeruginosa (CRPA), and carbapenem-resistant Acinetobacter baumannii (CRA) are considered 
as carbapenem-resistant organisms (CROs) [5]. Enterobacterales is an order of Gramnegative bacteria, comprising seven families and more than 80 genera. It incorporates pathogens accountable for $30 \%$ of HAIs [6]. The global priority list of pathogens by the World Health Organization (WHO) has categorized CRE, CRPA, and CRA as critical or highest priority [7].

Carbapenems have been the drugs of choice to cure critical VAP infections, although illogical and very common use of carbapenems has given rise to the emergence of CR-GNB strains. Resistance to carbapenems is mediated by a variety of mechanisms [4]. Carbapenemase enzymes, the most significant of these mechanisms, are $\beta$-lactamases that inactivate many $\beta$-lactam antibiotics. Carbapenemases belong to three classes amongst the four classes of $\beta$-lactamases defined by the Ambler classification. Class A contains serine in the active site of the enzyme (e.g., SME, IMI, NMC, GES and KPC), class B, metallo- betalactamases (MBLs) (e.g., IMP, NDM, VIM and GIM); and class D (OXA-like). Lately, it has become challenging to treat VAP because of the emergence of class B MBLs, which possess potent carbapenemase activity and are wide-ranging and resistance to almost all $\beta$-lactam antibiotics [8]. Gene coding for many carbapenemases are located on mobile genetic elements (MGEs), which could be spread between strains. Moreover, these MGEs often carry further genes that provide resistance to non- $\beta$-lactam antibiotics, further limiting treatment options for CR-GNB infections. It is therefore logical that carbapenem use would lead to the emergence of resistance [6,9-11].

Multidrug resistant bacteria (MDR) present a certain risk in hospitals, especially among patients who need procedures such as blood catheters and ventilators as they are more susceptible to serious and frequently fatal infections, such as bloodstream infections and pneumonia. These bacteria have developed a resistance to many antibiotics, including carbapenems and third generation cephalosporins which are the greatest available antibiotics for MDR bacteria. MDR implies resistance by the strains to three or more antimicrobial drug classes. Extensive drug resistance (XDR) implies resistance to all but two drug classes. Pan-drug resistance (PDR) implies resistance to all drug classes [12]. VAP has high risk of mortality and morbidity and may be attributable to inappropriate or delayed empirical antibiotic therapy, particularly when VAP is produced by MDR [13].

Our study was conducted to identify the frequency of CR-GNB infections in VAP patients at a chest and women's health hospital (WHH) ICUs, Assiut University Hospitals, Egypt, and to determine the frequency of MDR, XDR, and PDR among CR-GNB causing VAP.

\section{Results}

\subsection{Identification of the Bacterial Isolates}

Seventy-five pathogens were isolated from VAP patients. Of these, $57(76 \%)$ were Gram-negative bacilli, 16 (21.4\%) were Gram-positive cocci, and 2 (2.6\%) were Candida spp. Out of 57 Gram-negative bacilli isolates, Klebsiella pneumoniae was the most common isolate $(n=32)$, Klebsiella oxytoca $(n=1)$, E. coli $(n=5)$, Proteus vulgaris $(n=4)$, Pseudomonas aeruginosa $(n=11)$, and Acinetobacter baumannii $(n=4)$.

\subsection{Antimicrobial Susceptibility Testing}

The isolates showed $100 \%$ resistance to both ampicillin and cefaclor. They were highly resistant to meropenem $(94.7 \%)$, ciprofloxacin and norfloxacin (92.9\% for each), ceftriaxone $(94.7 \%)$, tobramycin $(89.4 \%)$, and imipenem $(80.7 \%)$. The anti-microbial susceptibility pattern of the isolates using the disk diffusion method is demonstrated in Tables 1 and 2. 
Table 1. Antibiotic resistance profile of isolates from chest ICU.

\begin{tabular}{ccccccc}
\hline $\begin{array}{c}\text { Antimicrobial } \\
\text { Agent }\end{array}$ & $\begin{array}{c}\text { K. pneumoniae } \\
\boldsymbol{n = 2 9}\end{array}$ & $\begin{array}{c}\text { K. oxytoca } \\
\boldsymbol{n = 1}\end{array}$ & $\begin{array}{c}\text { E. coli } \\
\boldsymbol{n}=\mathbf{3}\end{array}$ & $\begin{array}{c}\text { P. vulgaris } \\
\boldsymbol{n}=\mathbf{3}\end{array}$ & $\begin{array}{c}\text { P. aeruginosa } \\
\boldsymbol{n}=\mathbf{1 0}\end{array}$ & $\begin{array}{c}\text { A. baumannii } \\
\boldsymbol{n}=\mathbf{4}\end{array}$ \\
\hline Ampicillin & $100 \%$ & $100 \%$ & $100 \%$ & $100 \%$ & $100 \%$ & $100 \%$ \\
Cefaclor & $100 \%$ & $100 \%$ & $100 \%$ & $100 \%$ & $100 \%$ & $100 \%$ \\
Ceftriaxone & $100 \%$ & $100 \%$ & $66.7 \%$ & $66.7 \%$ & $100 \%$ & $100 \%$ \\
Imipenem & $89.6 \%$ & $100 \%$ & $100 \%$ & $66.7 \%$ & $100 \%$ & $50 \%$ \\
Meropenem & $96.5 \%$ & $100 \%$ & $100 \%$ & $100 \%$ & $100 \%$ & $100 \%$ \\
Ciprofloxcin & $100 \%$ & $100 \%$ & $100 \%$ & $100 \%$ & $100 \%$ & $100 \%$ \\
Norfloxacin & $100 \%$ & $100 \%$ & $100 \%$ & $100 \%$ & $100 \%$ & $100 \%$ \\
Tobramycins & $100 \%$ & $100 \%$ & $100 \%$ & $100 \%$ & $100 \%$ & $100 \%$ \\
\hline
\end{tabular}

Table 2. Antibiotic resistance profile of isolates from WHH ICU.

\begin{tabular}{ccccc}
\hline $\begin{array}{c}\text { Antimicrobial } \\
\text { Agent }\end{array}$ & $\begin{array}{c}\text { K. pneumoniae } \\
\boldsymbol{n = 3}\end{array}$ & $\begin{array}{c}\text { E. coli } \\
\boldsymbol{n}=\mathbf{2}\end{array}$ & $\begin{array}{c}\boldsymbol{P .} \text { vulgaris } \\
\boldsymbol{n}=\mathbf{1}\end{array}$ & $\begin{array}{c}\text { P. aeruginosa } \\
\boldsymbol{n}=\mathbf{1}\end{array}$ \\
\hline Ampicillin & $100 \%$ & $100 \%$ & $100 \%$ & $100 \%$ \\
Cefaclor & $100 \%$ & $100 \%$ & $100 \%$ & $100 \%$ \\
Ceftriaxone & $33.3 \%$ & $100 \%$ & $100 \%$ & $0 \%$ \\
Imipenem & $66.7 \%$ & $0 \%$ & $0 \%$ & $0 \%$ \\
Meropenem & $66.7 \%$ & $100 \%$ & $0 \%$ & $100 \%$ \\
Ciprofloxacin & $66.7 \%$ & $100 \%$ & $0 \%$ & $0 \%$ \\
Norfloxacin & $33.3 \%$ & $100 \%$ & $0 \%$ & $0 \%$ \\
Tobramycins & $0 \%$ & $50 \%$ & $0 \%$ & $0 \%$ \\
\hline
\end{tabular}

\subsection{Phenotypic Carbapenemase Detection}

E-test results showed that 36/57 (63.1\%) isolates were resistant to imipenem with MIC value ranging from $0.002-32 \mathrm{mg} / \mathrm{L}$.

The results of mCIM (using both meropenem and imipenem discs) revealed high level of resistance indicating potential carbapenemase production. Out of 57 isolates there were $43(75.4 \%)$ imipenem-resistant isolates and $36(63.1 \%)$ meropenem-resistant isolates.

The degree of agreement between disc diffusion method, E-test and mCIM for imipenem is shown in Table 3. There was a moderate significant agreement in the results as kappa level for E-test $=0.498$ and for $\mathrm{mCIM}=0.439$ and $p$-value $<0.001$.

Table 3. Correlation between results of phenotypic tests (disc diffusion, E-test and mCIM) for imipenem.

\begin{tabular}{|c|c|c|c|c|}
\hline & \multicolumn{2}{|c|}{ Disc Diffusion } & \multirow{2}{*}{$\begin{array}{c}\text { Kappa } \\
\text { Agreement }\end{array}$} & \multirow{2}{*}{$p$-Value } \\
\hline & Susceptible $(n=11)$ & Resistance $(n=46)$ & & \\
\hline \multicolumn{5}{|c|}{ E-test } \\
\hline Susceptible $(n=21)$ & $10(17.5 \%)$ & $11(19.3 \%)$ & \multirow{2}{*}{0.498} & \multirow{2}{*}{$<0.001^{\wedge}$} \\
\hline Resistance $(n=36)$ & $1(1.8 \%)$ & $35(61.4 \%)$ & & \\
\hline \multicolumn{5}{|c|}{$\mathrm{mCIM}$} \\
\hline Susceptible $(n=14)$ & $7(12.3 \%)$ & $7(12.3 \%)$ & \multirow{2}{*}{0.439} & \multirow{2}{*}{$0.001^{\wedge}$} \\
\hline Resistance $(n=43)$ & $4(7.0 \%)$ & $39(68.4 \%)$ & & \\
\hline
\end{tabular}

\subsection{Detection of Carbapenem Resistance Genes}

The isolates were tested by PCR for detection of $b l a_{\mathrm{NDM}}, b l a_{\mathrm{VIM}}, b l a_{\mathrm{SPM}}, b l a_{\mathrm{IMP}}$, and $b l a_{\mathrm{GIM}}$ genes. The frequency of the evaluated genes was: $b l a_{\mathrm{NDM}}(89.5 \%), b l a_{\mathrm{VIM}}(14 \%)$, $b l a_{\mathrm{SPM}}(17.5 \%), b l a_{\mathrm{IMP}}(10.5 \%)$ and $b l a_{\mathrm{GIM}}(3.5 \%)$. bla $a_{\mathrm{NDM}}$ was the most predominant gene. The co-existence of carbapenemase-producing genes $\left(b a_{\mathrm{NDM}, \mathrm{VIM}, \mathrm{SPM}, \mathrm{GIM}}\right)$ was detected in 19 strains (14 strains had 2 genes, 4 strains had 3 genes, and 1 strain had 4 resistance genes). 33 strains had only one resistance gene (32 strains had $b l a_{\mathrm{NDM}}$ and one strain had $b l a_{\mathrm{IMP}}$ ). 
While 5 strains did not have any resistance gene. Table 4 demonstrates the genetic profile of the isolated strains.

Table 4. Genetic profile of isolated strains.

\begin{tabular}{ccccccc}
\hline & Klebsiella & Escherichia & Proteus & Pseudomonas & Acinetobacter & All Strains \\
\hline NDM & $30(90.9 \%)$ & $5(100 \%)$ & $3(75 \%)$ & $10(90.9 \%)$ & $3(75 \%)$ & $51(89.5 \%)$ \\
VIM & $2(6.1 \%)$ & 0 & 0 & $6(54.5 \%)$ & 0 & $8(14 \%)$ \\
SPM & $8(24.2 \%)$ & 0 & 0 & $2(18.2 \%)$ & 0 & $10(17.5 \%)$ \\
IMP & $3(9.1 \%)$ & $1(20 \%)$ & 0 & 0 & $2(50 \%)$ & $6(10.5 \%)$ \\
GIM & $2(6.1 \%)$ & 0 & 0 & 0 & 0 & $2(3.5 \%)$ \\
\hline
\end{tabular}

The association between carbapenem-resistant genes and imipenem-resistant strains (regarding $\mathrm{mCIM}$ ) is shown in Table 5 and the association between carbapenem-resistant genes and meropenem-resistant strains (regarding mCIM) is shown in Table 6.

Table 5. Association between resistance genes and imipenem resistant strains (regarding mCIM).

\begin{tabular}{cccccc}
\hline & Klebsiella & Escherichia & Protus & Pseudomonas & Acinetobacter \\
\hline NDM & $26(92.9 \%)$ & $3(100 \%)$ & $2(100 \%)$ & $7(100 \%)$ & $2(66.7 \%)$ \\
VIM & $2(7.1 \%)$ & 0 & 0 & $6(85.7 \%)$ & 0 \\
SPM & $7(25.0 \%)$ & 0 & 0 & $2(28.6 \%)$ & 0 \\
IMP & $3(10.7 \%)$ & $1(33.3 \%)$ & 0 & 0 & $2(66.7 \%)$ \\
GIM & $2(7.1 \%)$ & 0 & 0 & 0 & 0 \\
\hline
\end{tabular}

Table 6. Association between resistance genes and meropenem resistant strains (regarding mCIM).

\begin{tabular}{cccccc}
\hline & Klebsiella & Escherichia & Proteus & Pseudomonas & Acinetobacter \\
\hline NDM & $20(90.9 \%)$ & $2(100 \%)$ & $2(66.7 \%)$ & $7(100 \%)$ & $2(100 \%)$ \\
VIM & $2(9.1 \%))$ & 0 & 0 & $6(85.7 \%)$ & 0 \\
SPM & $7(31.8 \%)$ & 0 & 0 & $2(28.6 \%)$ & 0 \\
IMP & $2(9.1 \%)$ & 0 & 0 & 0 & $1(50 \%)$ \\
GIM & $1(4.5 \%)$ & 0 & 0 & 0 & 0 \\
\hline
\end{tabular}

The degree of agreement between genotypic and phenotypic methods for detection of resistant strains is demonstrated in Table 7. There was a slight significant agreement between PCR and E-test as kappa level $=0.193$ and moderate significant agreement between PCR and disc diffusion test.

Analysis of the basic medical history, history of antibiotic use, immune status, prolonged intubation, reintubation, invasive operation, and length of hospital stay was performed. The results revealed that the incidence of carbapenem-resistant $K$. pneumoniae (CRKP) was slightly higher in patients aged more than 50 years and increased with a longer hospital stay. 
Table 7. Agreement between genotypic and phenotypic tests.

\begin{tabular}{|c|c|c|c|c|}
\hline \multirow[b]{2}{*}{ Phenotypic } & \multicolumn{2}{|c|}{ PCR Genes } & \multirow[b]{2}{*}{$\begin{array}{c}\text { Kappa } \\
\text { Agreement }\end{array}$} & \multirow[b]{2}{*}{$p$-Value } \\
\hline & $\begin{array}{c}\text { Negative } \\
\text { (Susceptible) } \\
(n=5)\end{array}$ & $\begin{array}{c}\text { Positive } \\
\text { (Resistant) } \\
(n=52)\end{array}$ & & \\
\hline \multicolumn{5}{|c|}{ E-test } \\
\hline Susceptible $(n=21)$ & $4(7 \%)$ & $17(29.8 \%)$ & \multirow{2}{*}{0.193} & \multirow{2}{*}{$0.036^{\wedge}$} \\
\hline Resistance $(n=36)$ & $1(1.8 \%)$ & $35(61.4 \%)$ & & \\
\hline \multicolumn{5}{|c|}{ mCIM (Meropenem) } \\
\hline Susceptible $(n=21)$ & $2(3.5 \%)$ & $19(33.3 \%)$ & \multirow{2}{*}{0.004} & \multirow{2}{*}{0.878} \\
\hline Resistance $(n=36)$ & $3(5.3 \%)$ & $33(57.9 \%)$ & & \\
\hline \multicolumn{5}{|c|}{ mCIM (Imipenem) } \\
\hline Susceptible $(n=14)$ & $3(5.3 \%)$ & $11(19.3 \%)$ & \multirow{2}{*}{0.040} & \multirow{2}{*}{0.054} \\
\hline Resistance $(n=43)$ & $2(3.5 \%)$ & $41(71.9 \%)$ & & \\
\hline \multicolumn{5}{|c|}{ Disc diffusion (Meropenem) } \\
\hline Susceptible $(n=3)$ & $2(3.5 \%)$ & $1(1.8 \%)$ & \multirow{2}{*}{0.465} & \multirow{2}{*}{$<0.001^{\wedge}$} \\
\hline Resistance $(n=54)$ & $3(5.3 \%)$ & $51(89.5 \%)$ & & \\
\hline \multicolumn{5}{|c|}{ Disc diffusion (Imipenem) } \\
\hline Susceptible $(n=11)$ & $4(7 \%)$ & $7(12.3 \%)$ & \multirow{2}{*}{0.431} & \multirow{2}{*}{$<0.001^{\wedge}$} \\
\hline Resistance $(n=46)$ & $1(1.8 \%)$ & $45(78.9 \%)$ & & \\
\hline
\end{tabular}

\section{Discussion}

The present study aims to identify the frequency of CR-GNB infections in VAP patients and to determine the frequency of MDR, XDR and PDR among CR-GNB causing VAP infections, especially since the rapid and precise detection of carbapenemase-producing isolates has proven difficult for laboratories and entails phenotypic and genotypic analysis.

In this study, 57 Gram-negative strains were isolated from VAP patients and amongst them Klebsiella spp. was the predominant isolate $(n=33,57.9 \%)$. This correlates with a previous study in Egypt which declared that the most common pathogen for CR-GNB cases was Klebsiella spp. followed by E. coli [14]. However, our results were slightly higher than the incidence observed by Mohamed et al. Their samples were collected from patients admitted to different wards at Assiut University Hospital in Egypt. They declared that Klebsiella spp. was among the most common pathogens in intensive care units with a prevalence of ( $n=16,48.48 \%)$. Our different findings may be due to the fact that our samples were taken only from VAP patients, and that K. pneumoniae has been revealed as the major organism causing hospital-acquired infections involving pneumonia [15].

In agreement with our results, Gajdacs et al. detected 50 CR-GNB isolates; the majority of which were Klebsiella spp. (K. pneumoniae $(n=34)$, Klebsiella oxytoca $(n=1))$, while E. coli $(n=12)$ and E. cloacae $(n=3)$ [16]. On the other hand, Rezai et al. in Iran found that it was not K. pneumoniae but Pseudomonas aeruginosa with an incidence of $24.4 \%$ with the most significant pathogen causing VAP; this could be attributed to the geographical difference between the countries [17].

In the current study the prevalence of K. pneumoniae was slightly higher in patients aged more than 50 years, but this was not statistically significant compared to those less than 50 years; $53.8 \%, 57.1 \%$ and, $62.5 \%$ of VAP patients stayed in the hospital $\leq 7$ days, (8-14) days, >14 days, respectively, and the prevalence of K. pneumoniae increased with longer hospital stay, but different durations of hospital stay were statistically insignificant. Additionally, Kotb et al. in Egypt stated that a longer ICU stay prior to specimen collection was significantly associated with carbapenem resistance [14]. However, our findings were higher than the incidence observed by Khairy et al. in Minia, Egypt. Their study showed that $(37.5 \%)$ of patients were reported with a length of hospital stay (LOS) $>10$ days, 
followed by (28.2\%) with 8-10 days [18]. This may be attributable to the spread of resistant strains of K. pneumonia among VAP patients and the improper use of combined antibiotics as empirical treatment.

In the present study, $100 \%$ of isolates were resistant to both Cefaclor and Ampicillin. This agreed with a recent study conducted in Ethiopia. They found that 95 (35.2\%) out of 270 patients in the ICU have got infections with ESBL and carbapenemase releasing Gram-negative bacilli (GNB) and all GNB isolates were $100 \%$ resistant to both tetracycline and ampicillin [19]. We also found that $94.7 \%$ of isolates were resistant to ceftriaxone, even though, in a previous study in Iraq in 2016 the rate of resistance was $95.83 \%$ for ampicillin and $79.17 \%$ for ceftriaxone [20]. A study in Iran revealed that $15.53 \%$ of the P. aeruginosa and $97.4 \%$ of the A. baumannii isolates were screened as imipenem-resistant [21]. Another recent study in Zambia detected imipenem-resistance in $6 \%$ of $P$. aeruginosa and $18.2 \%$ of Acinetobacter species isolates [22]. In contrast, we found that $90.9 \%$ of the P. aeruginosa and $50 \%$ of A. baumannii isolates were imipenem resistant. Our findings almost concur with a study in Korea, which stated that the antibiotic resistance profile of CRKP was $29 / 45(64.4 \%)$ for imipenem and 36/45 (80.0\%) for meropenem [23]. Due to the rapid and different protocols for antibiotics use, there is a variation between our findings and the described studies.

The current study revealed that $76 \%$ of isolates were pan-drug resistant, $17 \%$ were extreme-drug resistant, and $7 \%$ were multidrug resistant. In addition, another study in Egypt detected that all 50 CRKP isolates were multidrug resistant (MDR) [24]. These values may be attributable to the absence of an appropriate antibiotic strategy used for VAP patients, ensuing long and improper use of antimicrobial agents, which has ultimately resulted in marked antibiotic resistance. Management based on empirical broad-spectrum antibiotics and the widespread use of over-the-counter antibiotics in Egypt have led to massive selection pressure and an MDR crisis that is likely to become considerably worse in the perspective future.

E-test was performed for imipenem, and we observed that $36.9 \%$ (21/57 isolates) were imipenem-resistant. By performing mCIM test we also detected that $24.6 \%$ (14/57 isolates) and $36.9 \%$ (21/57 isolates) were resistant to both imipenem and meropenem, respectively. In the USA, Pierce et al., found that 91 of the 92 isolates characterized as bearing carbapenemase genes showed positive results by mCIM [25]. This difference can be explained by the fact that all the isolates in the USA study were formerly characterized as bearing carbapenemase genes. Another possible explanation is that mCIM might have missed few carbapenemase producers, which probably possessed low-level of carbapenemase activities.

Although disc diffusion is a preliminary method with lower sensitivity than other methods, we observed a moderate significant agreement between it and both E-test and mCIM for imipenem (kappa level for E-test $=0.498$ and for $\mathrm{mCIM}=0.439$ and $p$-value $<0.001)$. The mCIM test is simple, low cost, does not require any equipment, and is easy to interpret. However, the relative long incubation time (from $8 \mathrm{hr}$ to overnight) cannot be ignored. Another limitation for MCIM is that it is incapable of verifying the carbapenemase class.

We noticed a discrepancy between $b l a_{\mathrm{NDM}}$-producing isolate and $\mathrm{mCIM}$, which produced an indeterminate result (counted as negative), in contrast to a previous study in New Zealand, they found the discrepancy between $b l a_{\mathrm{VIM}}$-producing isolate and the $\mathrm{mCIM}$ [26].

The genotypic analysis revealed that, $91.2 \%(52 / 57)$ of isolates had at least one resistance gene. However, it is very likely that the existence of only one carbapenem-resistance gene is not necessary associated with carbapenem-resistance. Contrary to what was previously noted in a study performed in Sudan, which revealed that $83 \%$ of isolates were positive by phenotypic tests, while $58.7 \%$ had one or more carbapenem-resistance genes [27].

In this study $89.5 \%, 14 \%, 17.5 \%, 10.5 \%, 3.5 \%$ of 57 isolates exhibited the presence of $b l a_{\mathrm{NDM}}, b l a_{\mathrm{VIM}}, b l a_{\mathrm{SPM}}, b l a_{\mathrm{IMP}}$ and $b l a_{\mathrm{GIM}}$, respectively, and $b l a_{\mathrm{NDM}}$ was the predominant gene by $89.5 \%$ (51/57 isolates). Our findings are consistent with previous studies in Egypt. 
Tawfick et al. detected that $b l a_{\text {NDM }}$ was the most prevalent genotype of carbapenemases by $68.88 \%(93 / 135)$. Furthermore, El-Domany et al. stated that the incidence of $b l a_{\mathrm{NDM}}$ was $70.0 \%[24,28]$. On the other hand, Ghaith et al., detected that the most prevalent carbapenemase gene was bla $a_{\text {OXA-48 }}$ which was identified in 14/23 (60.8\%) isolates followed by $b l a_{\mathrm{NDM}}$, which was identified in 12/23 (52.2\%) isolates [29]. Additionally, in a previous study in Assiut, El-rehewy et al. stated that $17.92 \%$ out of 97 isolates were positive to $b l a_{\mathrm{IMP}}$ gene and $16.42 \%$ were positive to $b l a_{\mathrm{VIM}}$ gene [30], even though our results differ from a published study in Sudan, which stated that $b l a_{\mathrm{IMP}}$ gene was harbored by $6.7 \%$ of carbapenem-resistant isolates [31]. In India, Kumari et al. stated that $58.6 \%$ of VAP patients had high resistance to carbapenems. Of their 172 isolates, $21.5 \%$ exhibited the presence of $b l a_{\text {NDM }}$ genes, $17.4 \%$ exhibited the presence of $b l a_{\mathrm{VIM}}$ gene and $8.7 \%$ isolates harbored both $b l a_{\mathrm{NDM}}$ and $b l a_{\mathrm{VIM}}$ genes. None of the isolates contained $b l a_{\mathrm{IMP}}$ gene [32]. Sękowska et al. confirmed that $b l a_{\mathrm{NDM}}$ and $b l a_{\mathrm{VIM}}$ genes are the main antibiotic-resistance genes that induce resistance patterns to carbapenems among VAP patients in Poland [9]. Another study in Thailand reported that $b l a_{\mathrm{NDM}}$ was the most common carbapenen-resistant gene, present in $65 \%$ isolates [3]. These concur well with our findings. However, Yan et al. in China detected that $89 \%$ of the carbapenen-resistant isolates were carbapenemase genepositive, including $70 \% b l a_{\mathrm{KPC}}, 13 \% b l a_{\mathrm{NDM}}, 6 \% b l a_{\mathrm{IMP}}$, and $1 \%$ combined $b l a_{\mathrm{KPC}} / b l a_{\mathrm{NDM}}$ genes [4].

CRKP plays a major role in VAP. In this study, $b l a_{\mathrm{NDM}}$ was the most prevalent gene among K. pneumoniae isolates. Concurring with our finding, a study in India found $b l a_{\mathrm{NDM}}$ in $28.8 \%$ and $b l a_{\mathrm{VIM}}$ in $17.7 \%$ of $K$. pneumoniae isolates among VAP patients [32]. However, a study from Iran revealed that $b a_{\mathrm{VIM}}$ was the most prevalent gene $(13.6 \%)$, while both $b l a_{\mathrm{IMP}}$ and $b l a_{\mathrm{NDM}}$ were only detected in two K. pneumoniae isolates [33], which is not in concordance with our findings.

All E. coli isolates in the present study exhibited the presence of $b l a_{\mathrm{NDM}}$ gene. This is in accordance with another study in China which stated that the most prevalent carbapenemase gene among E. coli isolates was bla $a_{\mathrm{NDM}}$ [34].

In the current study, P. aeruginosa isolates harbored bla $a_{\mathrm{NDM}}(90.9 \%)$ followed by $b \mathrm{la}_{\mathrm{VIM}}$ (54.5\%) and $b l a_{\mathrm{SPM}}(18.2 \%)$. Similarly, in a study in Iran, bla $a_{\mathrm{NDM}}$ was the most prevalent gene among $P$. aeruginosa isolates [35]. Additionally, high-levels of carbapenem-resistance induced by bla $a_{\mathrm{NDM}}$ and bla $a_{\mathrm{VIM}}$ were found in A. baumannii and P. aeruginosa isolates in a Libyan hospital [36]. A study in Saudi-Arabia detected $b l a_{\mathrm{VIM}}$ and $b l a_{\mathrm{GIM}}$ alone in $46 \%$ and $15 \%$ of $P$. aeruginosa isolates and $b l a_{\mathrm{NDM}}$ was not detected in any of the isolates. These results contradict our findings regarding $b l a_{\mathrm{NDM}}$ and $b l a_{\mathrm{GIM}}$ [37].

In the present study, Acinetobacter isolates harbored $b l a_{\mathrm{NDM}}(75 \%)$ and $b l a_{\mathrm{IMP}}(50 \%)$. Another study corroborates with our results, as bla NDM was detected in $65.6 \%$ of Acinetobacter isolates among VAP patients [38].

Despite being a global issue, there is a disparate distribution of AMR among countries, with more impact on developing countries $[13,15,17]$. This difficult burden on developing countries may be attributed to inadequate approaches to new antibiotics, expanded economic burden, and inability to afford second-line antibiotics, which may be more costly, thus producing worse outcomes. Moreover, in developing countries, improper infection prevention and control (IPC) measures have increased the incidence of AMR [39].

Limitations to the current study include the relatively small sample size and the lack of multiple gene types. Unfortunately, we were unable to perform whole-genome sequencing because of resource inaccessibility.

\section{Materials and Methods}

\subsection{Specimen Collection}

Study samples were collected over a period of 9 months (from May 2019 to January 2020) from chest and WHH ICUs, Assiut University Hospitals. Only patients showing bacteriologically verified pneumonia were investigated; establishing etiologic diagnosis re- 
quired the isolation of bacteria in considerable quantity from lower respiratory tract secretions samples.

The study was performed on 35 VAP patients, $23(66 \%)$ of them were males and $12(34 \%)$ were females. The median age of studied patients was (60 (20-85) years old) with a mean age of $60.4 \pm 15.7$. The median of the length of ICU stay was 12 (5-30) days. All patients received antibiotics before the collection of samples; 9,17 , and 9 patients received antibiotics for $\leq 7$ days, (8-14) days, and $>14$ days, respectively, and $10(28.6 \%)$ patients received combined antibiotics during their hospital stay.

\subsection{Identification of the Recovered Bacterial Isolates}

Isolates were categorized based on their Gram reactions. Gram-negative isolates were selected for further study. Culture characteristics on Nutrient agar, Blood agar, MacConkey's agar, and Eosin Methylene Blue (EMB) agar were recorded. Biochemical tests, including urease test, oxidase test, Triple sugar iron agar and citrate utilization test were performed. Identification was confirmed using API20E kits (Liofilchem, Roseto, Italy).

\subsection{Antimicrobial Susceptibility Testing}

Antimicrobial susceptibility testing was conducted using the disc diffusion method according to CLSI instructions [40]. The following antimicrobial discs (Oxoid, Basingstoke, Hampshire, UK) were used: Ampicillin $(10 \mu \mathrm{g})$, Cefaclor $(30 \mu \mathrm{g})$, Ceftriaxone $(30 \mu \mathrm{g})$, Tobramycin $(10 \mu \mathrm{g})$, Ciprofloxacin $(5 \mu \mathrm{g})$, Norofloxacin $(10 \mu \mathrm{g})$, Imipenem $(10 \mu \mathrm{g})$, Meropenem $(10 \mu \mathrm{g})$.

\subsection{Phenotypic Carbapenemase Detection}

All isolates were tested for accurate determination of their MIC using the imipenem-E test strips (Liofilchem, Roseto, Italy). Results were interpreted using CLSI breakpoints. A cut-off point of $\geq 4 \mu \mathrm{g} / \mathrm{mL}$ was to define imipenem-resistance and a cut-off point of $\leq 1 \mu \mathrm{g} / \mathrm{mL}$ was to define imipenem-susceptibility [40].

The modified carbapenem-inactivation method ( $\mathrm{mCIM}$ ) was used by both meropenem and imipenem discs. $1 \mu \mathrm{L}$ calibrated loopful of organism was suspended in $2 \mathrm{~mL}$ trypticase soy broth (TSB) and the suspension was vortexed for $15 \mathrm{~s}$. Then, 10- $\mu \mathrm{g}$ meropenem or imipenem disc (Oxoid, Hampshire, UK) was added into the suspension aseptically. The suspension including the disc was subsequently incubated at $35-37{ }^{\circ} \mathrm{C}$ for $4 \mathrm{~h}$. Then meropenem or imipenem disc was eliminated from the suspension using a $10-\mu \mathrm{L}$ inoculating loop; the loop was dragged along the edge of the tube to remove excess liquid during removal, and instantly put on Mueller-Hinton (MHA) plate which was inoculated with a $0.5 \mathrm{McF}$ arland suspension of standard carbapenem-susceptible E. coli strain ATCC ${ }^{\circledR}$ 25,922 (mCIM indicator organism). The plates were incubated at $35-37^{\circ} \mathrm{C}$ overnight; the inhibition zone around the disc was measured. Inhibition zone $6-15 \mathrm{~mm}$ or existence of colonies in a 16-18 $\mathrm{mm}$ zone was considered carbapenemase positive. While inhibition zone $\geq 19 \mathrm{~mm}$ was considered carbapenemase negative [25].

\subsection{Molecular Testing for Carbapenemase Genes}

Amplification of carbapenem-resistance encoding genes $\left(b l_{\text {NDM,VIM,SPM,IMP,GIM }}\right)$ was carried out by PCR using the proper primers (Table 8) [30,41-43]. Primers were manufactured by (Thermo Fisher Scientific, Waltham, MA, USA). The amplicons were analyzed by agarose gel electrophoresis, and the expected DNA product size was determined by comparing with an $1100 \mathrm{bp}$ DNA ladder (Willowfort, Birmingham, UK). 
Table 8. Sequence and expected product sizes of primers used for amplification of $b l a_{\mathrm{NDM}, \mathrm{VIM}, \mathrm{SPM}, \mathrm{IMP}, \mathrm{GIM}}$ genes.

\begin{tabular}{|c|c|c|}
\hline Amplicon Size (bp). & Nucleotide Sequence $\left(5^{\prime}-3^{\prime}\right)$ & Primers \\
\hline \multirow{3}{*}{200} & F (-CGAAAGTCAGGCTGTGTTGCGC-) & \\
\hline & R (-GACCGCCCAGATCCTCAACTG-) & $b l a_{\mathrm{NDM}}$ \\
\hline & F (-TCT ACA TGA CCG CGT CTG TC-) & \\
\hline \multirow[t]{2}{*}{747} & R (-TGT GCT TTG ACA ACG TTC GC-) & $b l a_{\mathrm{VIM}}$ \\
\hline & F (-CTGGCAGGGATCGCTCACTC -) & \\
\hline \multirow[t]{2}{*}{604} & R (-GGTTTCCGATCAGCCACCTCTCA-) & $b l a_{\mathrm{SPM}}$ \\
\hline & F (-TGAGCAAGTTATCTGTATTC-) & \\
\hline \multirow[t]{2}{*}{740} & R (-TTAGTTGCTTGGTTTTGATG-) & $b l a_{\mathrm{IMP}}$ \\
\hline & F (-TCCAGAACCTTGACCGAACG-) & \\
\hline 1062 & R (-GCCACTCATAGAGCATCGCA-) & $b l a_{\mathrm{GIM}}$ \\
\hline
\end{tabular}

\section{Conclusions}

This work has highlighted that CR-GNB, especially CRKP, caused a considerable percentage of VAP infections in chest and WHH ICUs, Assiut University hospitals. Our data revealed high levels of resistance to most antibiotics. Carbapenem-resistance genes were identified in a significant percentage of isolates and $b l a_{\mathrm{NDM}}$ was the most predominant one.

This serious issue emphasizes the urgent need to implement evidence-based IPC strategies to prevent CR-GNB transmission and incorporate antibiotic stewardship programs in order to decrease the CR-GNB burden. In an era of increasing antimicrobial bacterial resistance, rapid identification of carbapenemase-positive strains is not only critical in preventing spread, but also an epidemiological and economic issue, especially in developing countries such as Egypt.

Author Contributions: Conceptualization: M.I. Methodology: A.M., A.N. Validation: E.D. Investigation: A.M., A.N. Resources; A.N., L.S. Data Curation: A.M., L.S. Formal analysis: A.M. WritingOriginal Draft Preparation: A.M. Writing-Review and Editing: M.I. Visualization: M.I. Supervision: E.D. Project Administration: E.D., M.I. Funding Acquisition: M.I. All authors have read and agreed to the published version of the manuscript.

Funding: This research was funded by [Assiut Medical School Grants Office] grant number [2019-01-17-005].

Institutional Review Board Statement: The study was approved by the Faculty of Medicine, Institutional Review Board, Assiut University, ethics committee (IRBno: 17300120, Date: 17 January 2019).

Informed Consent Statement: Patient consent was waived because they were on mechanical ventilation that needed sedation to maintain comfort or were in coma due to their underlying critical illness.

Data Availability Statement: Not applicable.

Acknowledgments: Deep thanks to Mariam Taher Mohamed Amin. Assistant lecturer of public health and community medicine, Assiut University for her Contribution in Statistical Analysis.

Conflicts of Interest: The authors declare no conflict of interest.

\section{References}

1. Huang, J.; Cui, C.; Zhou, S.; Chen, M.; Wu, H.; Jin, R.; Chen, X. Impact of multicenter unified enhanced environmental cleaning and disinfection measures on nosocomial infections among patients in intensive care units. J. Int. Med. Res. 2020, 48. [CrossRef]

2. He, Q.; Wang, W.; Zhu, S.; Wang, M.; Kang, Y.; Zhang, R.; Zou, K.; Zong, Z.; Sun, X. The epidemiology and clinical outcomes of ventilator-associated events among 20,769 mechanically ventilated patients at intensive care units: An observational study. Crit. Care 2021, 25, 44. [CrossRef]

3. Paveenkittiporn, W.; Lyman, M.; Biedron, C.; Chea, N.; Bunthi, C.; Kolwaite, A.; Janejai, N. Molecular epidemiology of carbapenem-resistant Enterobacterales in Thailand, 2016-2018. Antimicrob. Resist. Infect. Control 2021, 10, 136. [CrossRef]

4. Yan, W.J.; Jing, N.; Wang, S.M.; Xu, J.H.; Yuan, Y.H.; Zhang, Q.; Li, A.L.; Chen, L.H.; Zhang, J.F.; Ma, B.; et al. Molecular characterization of carbapenem-resistant Enterobacteriaceae and emergence of tigecycline non-susceptible strains in the Henan province in China: A multicentrer study. J. Med. Microbiol. 2021, 70, 001325. [CrossRef] [PubMed] 
5. Kois, A.K.; Nicolau, D.P.; Kuti, J.L. Unresolved issues in the identification and treatment of carbapenem-resistant Gram-negative organisms. Curr. Opin. Infect. Dis. 2020, 33, 482-494. [CrossRef]

6. Shugart, A.; Mahon, G.; Huang, J.Y.; Karlsson, M.; Valley, A.; Lasure, M.; Gross, A.; Pattee, B.; Vaeth, E.; Brooks, R.; et al. Carbapenemase production among less-common Enterobacterales genera: 10 US sites, 2018. JAC-Antimicrob. Resist. 2021, 3. [CrossRef] [PubMed]

7. Global Priority List of Antibiotic-Resistant Bacteria to Guide Research, Discovery, and Development of New Antibiotics. Available online: http://www.who.int/medicines/publications/WHO-PPL-Short_Summary_25Feb-ET_NM_WHO.pdf (accessed on 18 October 2021).

8. Breijyeh, Z.; Jubeh, B.; Karaman, R. Resistance of Gram-Negative Bacteria to Current Antibacterial Agents and Approaches to Resolve It. Molecules 2020, 25, 1340. [CrossRef]

9. Sekowska, A.; Bogiel, T.; Kaczmarek, A. Evaluation of the usefulness of selected methods for the detection of carbapenemases in Klebsiella strains. J. Med. Microbiol. 2020, 69, 792-796. [CrossRef]

10. Fang, L.; Lu, X.; Xu, H.; Ma, X.; Chen, Y.; Liu, Y.; Hong, G.; Liang, X. Epidemiology and risk factors for carbapenem-resistant Enterobacteriaceae colonisation and infections: Case-controlled study from an academic medical center in a southern area of China. Pathog. Dis. 2019, 77. [CrossRef] [PubMed]

11. Bouganim, R.; Dykman, L.; Fakeh, O.; Motro, Y.; Oren, R.; Daniel, C.; Lazarovitch, T.; Zaidenstein, R.; Moran-Gilad, J.; Marchaim, D. The Clinical and Molecular Epidemiology of Noncarbapenemase-Producing Carbapenem-Resistant Enterobacteriaceae: A Case-Case-Control Matched Analysis. Open Forum Infect. Dis. 2020, 7, ofaa299. [CrossRef]

12. Eatemadi, A.; Al Risi, E.; Kasliwal, A.; Al Záabi, A.; Moradzadegan, H.; Aslani, Z. A Proposed Evidence-Based Local Guideline for Definition of Multidrug-Resistant (MDR), Extensively Drug-Resistant (XDR) and Pan Drug-Resistant (PDR) Bacteria by the Microbiology Laboratory. Int. J. Curr. Sci. Res. Rev. 2021, 4. [CrossRef]

13. Rea-Neto, A.; Youssef, N.C.; Tuche, F.; Brunkhorst, F.; Ranieri, V.M.; Reinhart, K.; Sakr, Y. Diagnosis of ventilator-associated pneumonia: A systematic review of the literature. Crit. Care 2008, 12, R56. [CrossRef] [PubMed]

14. Kotb, S.; Lyman, M.; Ismail, G.; El Fattah, M.A.; Girgis, S.A.; Etman, A.; Hafez, S.; El-Kholy, J.; Zaki, M.E.S.; Rashed, H.-A.G.; et al. Epidemiology of Carbapenem-resistant Enterobacteriaceae in Egyptian intensive care units using National Healthcare-associated Infections Surveillance Data, 2011-2017. Antimicrob. Resist. Infect. Control 2020, 9, 2. [CrossRef] [PubMed]

15. Mohamed, E.; Halby, H.; Ali, M.; El-Baky, R.; Waly, N. Spreading of NDMI-Producing Klebsiella Pneumoniae in Different Wards at Assiut University Hospital. Am. J. Infect. Dis. Microbiol. 2020, 8, $24-28$.

16. Gajdács, M.; Ábrók, M.; Lázár, A.; Jánvári, L.; Tóth, Á.; Terhes, G.; Burián, K. Detection of VIM, NDM and OXA-48 producing carbapenem resistant Enterobacterales among clinical isolates in Southern Hungary. Acta Microbiol. Immunol. Hung. 2020, 67, 209-215. [CrossRef] [PubMed]

17. Rezai, M.S.; Ahangarkani, F.; Rafiei, A.; Hajalibeig, A.; Bagheri-Nesami, M. Extended-Spectrum Beta-Lactamases Producing Pseudomonas aeruginosa Isolated from Patients with Ventilator Associated Nosocomial Infection. Arch. Clin. Infect. Dis. 2018, 13. [CrossRef]

18. Khairy, R.M.M.; Mahmoud, M.S.; Shady, R.R.; Esmail, M.A.M. Multidrug-resistant Klebsiella pneumoniae in hospital-acquired infections: Concomitant analysis of antimicrobial resistant strains. Int. J. Clin. Pract. 2019, 74, e13463. [CrossRef]

19. Alebel, M.; Mekonnen, F.; Mulu, W. Extended-Spectrum $\beta$-Lactamase and Carbapenemase Producing Gram-Negative Bacilli Infections Among Patients in Intensive Care Units of Felegehiwot Referral Hospital: A Prospective Cross-Sectional Study. Infect. Drug Resist. 2021, 14, 391-405. [CrossRef]

20. Aziz, R.; Al-jubori, S. Genetic Elements Responsible for Extreme Drug Resistance (Xdr) in Klebsiella Pnumoniae Var Pnumoniae Isolated from Clinical Samples of Iraqi Patients. World J. Pharm. Res. 2016, 5, 1-23. [CrossRef]

21. Mirzaei, B.; Bazgir, Z.N.; Goli, H.R.; Iranpour, F.; Mohammadi, F.; Babaei, R. Prevalence of multi-drug resistant (MDR) and extensively drug-resistant (XDR) phenotypes of Pseudomonas aeruginosa and Acinetobacter baumannii isolated in clinical samples from Northeast of Iran. BMC Res. Notes 2020, 13, 380. [CrossRef] [PubMed]

22. Kaluba, C.K.; Samutela, M.T.; Kapesa, C.; Muma, J.B.; Hang'Ombe, B.M.; Hachaambwa, L.; Mukomena, P.; Yamba, K. Carbapenem resistance in Pseudomonas aeruginosa and Acinetobacter species at a large tertiary referral hospital in Lusaka, Zambia. Sci. Afr. 2021, 13, e00908. [CrossRef]

23. Park, Y.; Choi, Q.; Kwon, G.C.; Koo, S.H. Molecular epidemiology and mechanisms of tigecycline resistance in carbapenemresistant Klebsiella pneumoniae isolates. J. Clin. Lab. Anal. 2020, 34, e23506. [CrossRef] [PubMed]

24. El-Domany, R.A.; El-Banna, T.; Sonbol, F.; Abu-Sayedahmed, S.H. Co-existence of NDM-1 and OXA-48 genes in Carbapenem Resistant Klebsiella pneumoniae clinical isolates in Kafrelsheikh, Egypt. Afr. Health Sci. 2021, 21, 489-496. [CrossRef]

25. Pierce, V.M.; Simner, P.J.; Lonsway, D.R.; Roe-Carpenter, D.E.; Johnson, J.K.; Brasso, W.B.; Bobenchik, A.M.; Lockett, Z.C.; Charnot-Katsikas, A.; Ferraro, M.J.; et al. Modified Carbapenem Inactivation Method for Phenotypic Detection of Carbapenemase Production among Enterobacteriaceae. J. Clin. Microbiol. 2017, 55, 2321-2333. [CrossRef]

26. Howard, J.; Creighton, J.; Ikram, R.; Werno, A. Comparison of the performance of three variations of the Carbapenem Inactivation Method (CIM, modified CIM [mCIM] and in-house method (iCIM)) for the detection of carbapenemase-producing Enterobacterales and non-fermenters. J. Glob. Antimicrob. Resist. 2020, 21, 78-82. [CrossRef] 
27. Elbadawi, H.S.; Elhag, K.M.; Mahgoub, E.; Altayb, H.N.; Ntoumi, F.; Elton, L.; McHugh, T.D.; Tembo, J.; Ippolito, G.; Osman, A.Y.; et al. Detection and characterization of carbapenem resistant Gram-negative bacilli isolates recovered from hospitalized patients at Soba University Hospital, Sudan. BMC Microbiol. 2021, 21, 136. [CrossRef]

28. Tawfick, M.M.; Alshareef, W.A.; Bendary, H.A.; Elmahalawy, H.; Abdulall, A.K. The emergence of carbapenemase blaNDM genotype among carbapenem-resistant Enterobacteriaceae isolates from Egyptian cancer patients. Eur. J. Clin. Microbiol. Infect. Dis. 2020, 39, 1251-1259. [CrossRef]

29. Ghaith, D.M.; Zafer, M.M.; Said, H.M.; Elanwary, S.; Elsaban, S.; Al-Agamy, M.H.; Bohol, M.F.F.; Bendary, M.M.; Al-Qahtani, A.; Al-Ahdal, M.N. Genetic diversity of carbapenem-resistant Klebsiella Pneumoniae causing neonatal sepsis in intensive care unit, Cairo, Egypt. Eur. J. Clin. Microbiol. Infect. Dis. 2019, 39, 583-591. [CrossRef]

30. El-rehewy, M.; Saboor, E.; Afifi, N.; Ibrahim, M.; Qayed, S. Detection and Characterization of Nosocomial Carbapenem- Resistant Gram-Negative Bacilli from Assiut University Hospitals. Egypt. J. Med. Microbiol. 2016, 25, 9-17. [CrossRef]

31. Dahab, R.; Ibrahim, A.M.; Altayb, H.N. Phenotypic and genotypic detection of carbapenemase enzymes producing gram-negative bacilli isolated from patients in Khartoum State. F1000Research 2017, 6, 1656. [CrossRef]

32. Kumari, M.; Verma, S.; Venkatesh, V.; Gupta, P.; Tripathi, P.; Agarwal, A.; Siddiqui, S.S.; Arshad, Z.; Prakash, V. Emergence of blaNDM-1 and blaVIM producing Gram-negative bacilli in ventilator-associated pneumonia at AMR Surveillance Regional Reference Laboratory in India. PLoS ONE 2021, 16, e0256308. [CrossRef]

33. Alizadeh, H.; Khodavandi, A.; Alizadeh, F.; Bahador, N. Molecular Characteristics of Carbapenem-Resistant Klebsiella pneumoniae Isolates Producing blaVIM, blaNDM, and blaIMP in Clinical Centers in Isfahan, Iran. Jundishapur J. Microbiol. 2021, 14. [CrossRef]

34. Han, R.; Shi, Q.; Wu, S.; Yin, D.; Peng, M.; Dong, D.; Zheng, Y.; Guo, Y.; Zhang, R.; Hu, F.; et al. Dissemination of Carbapenemases (KPC, NDM, OXA-48, IMP, and VIM) Among Carbapenem-Resistant Enterobacteriaceae Isolated from Adult and Children Patients in China. Front. Cell. Infect. Microbiol. 2020, 10, 314. [CrossRef] [PubMed]

35. Azimi, L.; Fallah, F.; Karimi, A.; Shirdoust, M.; Azimi, T.; Sedighi, I.S.; Rahbar, M.; Armin, S. Survey of various carbapenemresistant mechanisms of Acinetobacter baumannii and Pseudomonas aeruginosa isolated from clinical samples in Iran. Iran. J. Basic Med. Sci. 2020, 23, 1396-1400. [CrossRef]

36. Slimene, K.; El Salabi, A.A.; Dziri, O.; Mabrouk, A.; Miniaoui, D.; Gharsa, H.; Shokri, S.A.; Alhubge, A.M.; Achour, W.; Rolain, J.-M.; et al. High Carbapenem Resistance Caused by VIM and NDM Enzymes and OprD Alteration in Nonfermenter Bacteria Isolated from a Libyan Hospital. Microb. Drug Resist. 2021. [CrossRef] [PubMed]

37. Jawhar, W.; AlRashed, M.; Somily, A.; AlBarra, A. Molecular characterization of Carbapenem-resistance genes among Pseudomonas aeruginosa and Acinetobacter baumannii clinical isolates in Riyadh. Pharmacophore 2020, 11, 56-61.

38. Elbrolosy, A.M.; Labeeb, A.Z.; Hassan, D. New Delhi metallo- $\beta$-lactamase-producing Acinetobacter isolates among late-onset VAP patients: Multidrug-resistant pathogen and poor outcome. Infect. Drug Resist. 2019, 12, 373-384. [CrossRef] [PubMed]

39. Iwu-Jaja, C.J.; Jaca, A.; Jaja, I.F.; Jordan, P.; Bhengu, P.; Iwu, C.D.; Okeibunor, J.; Karamagi, H.; Tumusiime, P.; Fuller, W.; et al. Preventing and managing antimicrobial resistance in the African region: A scoping review protocol. PLoS ONE 2021, 16, e0254737. [CrossRef]

40. CLSI. Performance Standards for Antimicrobial Susceptibility, 29th ed.; CLSI Guideline M100; Clinical and Laboratory Standards Institute: Wayne, PA, USA, 2019.

41. Trung, N.T.; Hien, T.T.T.; Huyen, T.T.T.; Quyen, D.T.; Binh, M.T.; Hoan, P.Q.; Meyer, C.G.; Velavan, T.P.; Song, L.H. Simple multiplex PCR assays to detect common pathogens and associated genes encoding for acquired extended spectrum betalactamases (ESBL) or carbapenemases from surgical site specimens in Vietnam. Ann. Clin. Microbiol. Antimicrob. 2015, 14, 23. [CrossRef]

42. Liang, W.-J.; Liu, H.-Y.; Duan, G.-C.; Zhao, Y.-X.; Chen, S.-Y.; Yang, H.-Y.; Xi, Y.-L. Emergence and mechanism of carbapenemresistant Escherichia coli in Henan, China, 2014. J. Infect. Public Health 2017, 11, 347-351. [CrossRef]

43. Wendel, A.F.; MacKenzie, C.R. Characterization of a Novel Metallo- $\beta$-Lactamase Variant, GIM-2, from a Clinical Isolate of Enterobacter cloacae in Germany. Antimicrob. Agents Chemother. 2014, 59, 1824-1825. [CrossRef] [PubMed] 